\title{
TERRITORIALIDADE HOMOERÓTICA: APONTAMENTOS PARA OS ESTUDOS DE GÊNERO
}

\author{
Maria Juracy Filgueiras Toneli \\ Juliana Perucchi \\ Universidade Federal de Santa Catarina
}

\begin{abstract}
RESUMO: Este trabalho é resultado de uma pesquisa cujo objetivo foi investigar as relações sociais engendradas por mulheres que se relacionam afetiva e sexualmente com outras mulheres e que freqüentavam um espaço reconhecido como gueto GLS (gays, lésbicas e simpatizantes). A pesquisa foi desenvolvida como exercício etnográfico, com dados obtidos a partir de observações de campo e de entrevistas. Os dados foram analisados a partir da análise de conteúdo. Este artigo privilegia a abordagem dos sentidos atribuídos às relações que se estabelecem nesse espaço que se revela como mediação para constituição dos sujeitos. Destaca a territorialidade itinerante, o trânsito e as posições dos sujeitos em redes de sociabilidades. Os resultados evidenciam uma perspectiva de manutenção desses espaços sob uma configuração que se refere à separação dos públicos, muito mais do que uma possível agregação de diferentes públicos em locais compartilhados livremente. Contemplam problemáticas de igualdade/diferença, (in)visibilidade, proteção, exclusão, tolerância e preconceito.
\end{abstract}

PALAVRAS-CHAVE: territorialidade; homoerotismo; gênero.

\section{HOMOEROTIC TERRITORIALITY: NOTES FOR STUDIES ON GENDER}

ABSTRACT: This paper is the result of a research that investigated the social relations of women who have affective and sexual relationships with other women and who socialized at a place recognized as a GLS (gay, lesbian and sympathizers) ghetto. The research was developed as an ethnographic exercise, obtaining data through field observations and interviews. The data was analyzed by content analysis. This article privileges the approach of the meanings attributed by these women to the relations they have established at that location, and that is revealed as being a mediation in constituting the subjects. The errant territoriality, transit and the positions of the subjects in networks of sociability are highlighted. The results shows us a perspective of maintaining these places under a configuration that refers to the separation of people much more than a possible aggregation of different people in freely shared places. They contemplate the themes of equality/difference, (in)visibility, protection, exclusion, tolerance and prejudice.

KEYWORDS: territoriality; homoerotism; gender studies.

\section{Territorialidade homoerótica: apontamentos para um debate de gênero}

Este trabalho é resultado de uma pesquisa (Perucchi, 2001) cujo objetivo foi investigar as relações sociais engendradas por mulheres que se relacionam afetiva e sexualmente com outras mulheres e que freqüentavam um espaço reconhecido socialmente como gueto GLS. ${ }^{1}$ A pesquisa foi realizada na cidade de Florianópolis, ilha de Santa Catarina. O presente artigo privilegia a abordagem dos sentidos atribuídos às relações que se estabelecem nesse espaço que se revela como constructo sociológico, investigado a partir de uma perspectiva sócio-histórica em Psicologia. Destaca a territorialidade itinerante, o trânsito e as relações dos sujeitos em redes de sociabilidades. Territorialidade não apenas na dimensão física do espaço, ainda que tal dimensão seja fundamental para a delimitação de fronteiras do gueto, mas fundamentalmente como espaço simbólico constitutivo de modos de vida e de redes sociais a partir das quais sujeitos se constroem.

A pesquisa foi desenvolvida como trabalho etnográfico por meio do qual se estabeleceu o contato com as infor- mantes. Os dados foram obtidos em uma boate na área do centro da cidade de Florianópolis, a partir de observações de campo e de entrevistas semi-estruturadas. As questões do roteiro de entrevista foram formuladas a partir do objetivo geral da pesquisa: investigar as relações sociais engendradas por mulheres que se relacionam afetiva e sexualmente com outras mulheres e que freqüentavam um espaço reconhecido como gueto GLS (gays, lésbicas e simpatizantes) em Florianópolis. Transcorreram-se cinco semanas de observações de campo antes da abordagem das informantes de pesquisa para agendar as entrevistas. Os critérios para escolha das doze participantes da pesquisa foram basicamente dois: que tais mulheres tivessem naquele momento relações afetivo-sexuais exclusivamente com outras mulheres e que frequientassem a boate com certa regularidade e há algum tempo. O procedimento de análise dos dados foi realizado por meio da análise de conteúdo (Bardin, 1977), através da qual o material coletado foi organizado e categorizado sistematicamente em núcleos de sentidos que se destacaram do conteúdo que compõem a comunicação. A análise de conteúdo consiste no 
tratamento das mensagens, conteúdo e expressão desse conteúdo, evidenciando os indicadores que permitam inferir sobre uma outra realidade que não exclusivamente a da mensagem (Bardin, 1977) atribuindo à pesquisa um caráter exploratório, descritivo e analítico das informações coletadas ao longo da investigação.

Num primeiro momento, foi delimitado um território, privilegiando os espaços de diversão e lazer vinculados às afinidades e interesses do público GLS de camadas médias, divulgados e reconhecidos pela mídia local e por informativos turísticos como "boates gays". ${ }^{2}$ A escolha do estabelecimento em questão deu-se por critérios específicos relevantes à problemática proposta: era um espaço de lazer reconhecido como danceteria voltada a esse público e, apesar de haver outros locais (bares e uma outra danceteria), este era o ponto de encontro mais freqüentado. ${ }^{3}$ Tratava-se do espaço urbano com maior concentração de público e maior diversidade de pessoas, apesar de que, no que se refere à estratificação sócio-econômica, estamos estabelecendo um recorte a um espaço freqüentado preferencial, mas não exclusivamente, por pessoas oriundas de camadas médias. Além disso, alguns dos/as freqüentadores/as faziam parte da rede social da pesquisadora, o que se destacou como um facilitador para o acesso às informantes. Segundo Bott (1976, p. 299) “a rede é definida como todas ou algumas unidades sociais (indivíduos ou grupos) com as quais um indivíduo particular ou um grupo está em contato". Na pesquisa aqui relatada, tratou-se de uma rede pessoal na qual a pesquisadora estava em contato direto através de suas relações de amizade e coleguismo com as pessoas que freqüentavam o espaço da boate. Este procedimento de contato com as informantes de pesquisa por meio de rede social exigiu um posicionamento criterioso por parte da pesquisadora no sentido de tornar exótico o que lhe era familiar, promovendo um estranhamento metodológico frente à familiaridade do campo, pertinente ao processo de investigação. A trajetória de pesquisa foi atravessada por situações inusitadas em relação a tal estranhamento. A pesquisadora foi paquerada por algumas mulheres durante o trabalho de campo, em algumas situações, quando estava em campo na etapa de observação, a pesquisadora foi abordada por pessoas conhecidas que questionaram o fato de estar sozinha na boate, por fazer anotações em seu diário de campo, ou ainda, por reunir panfletos de divulgação das festas, disponíveis no caixa da boate. $\mathrm{O}$ olhar da pesquisadora também mergulhou em um estranhamento diante de situações que, quando freqüentadora daquele espaço, não eram percebidas e que, a partir do rigor metodológico imposto à observação, passaram a se destacar como elementos analíticos da investigação.

É fundamental destacar as especificidades dessas redes de sociabilidades constitutivas do gueto GLS de Florianópolis, na medida em que, se diferencia constitutivamente da definição proposta pela Escola de Chicago sobre a distribuição dos corpos nos espaços urbanos. As pessoas que transitavam no contexto aqui investigado não residiam, mas transitavam pelo local. Florianópolis não se configura como arranjo urbano semelhante ao evidenciado por Levine (1979), conforme discutiremos a seguir.

Considerando as perspectivas teóricas dos Estudos de Gênero, que sustentaram a presente investigação, é importante ressaltar a necessidade de se rejeitar o caráter fixo e permanente da oposição binária entre masculino e feminino (Scott, 1994) e a cristalização das características identitárias dos sujeitos (Fuller, 1997), privilegiando a historicização destas construções. Neste sentido, este trabalho contrapõe-se a reducionismos que buscam uma única explicação para as relações de gênero, a saber, a da dominação-opressão da supremacia masculina. Ao contrário, pretende-se considerar a complexidade e o caráter relacional da questão, bem como, as formas de poder exercidas também pelas mulheres no âmbito das relações sociais que estabelecem no contexto pesquisado.

\section{Gueto: categoria nativa e categoria de análise}

A decisão de trabalhar com o conceito de gueto foi condicionada pela revisão de literatura sobre a ocupação, deliberada ou não, e a organização espacial urbana por grupos minoritários. A partir do clássico The Guetto, de Wirth (1969), Levine (1979) se propõe a investigar em que medida as concepções definidas pela Escola de Chicago cabem aos bairros habitados predominantemente por gays e lésbicas, nas cidades de Chicago, Boston, Los Angeles e Nova Iorque (Perlongher, 1988). Entretanto, o conceito originalmente cunhado por Wirth contempla um argumento peculiar a tais ocupações, do caráter não deliberado destas organizações espaciais, o que parece ocorrer inversamente nas experiências gays de organização espacial nas cidades norte americanas, como afirma Castells (1984):

Mas qualquer que seja a coincidência que possa existir entre as características do gueto, como definido pela Escola de Chicago, e a experiência gay de organização espacial, trata-se de argumento meramente formal e, em certos casos, enganador. De sua parte, os líderes gays preferem falar de zonas liberadas, e existe uma diferença teórica maior entre as duas noções: os territórios gays, diferentemente dos guetos, são construídos deliberadamente pelas pessoas gays (p.139).

Ocorre que, para Levine (1979), a validade da noção de gay ghetto aos espaços urbanos de cidades norte-americanas se confirma pelo fechamento dos requisitos de concentração institucional, de área de cultura, de isolamento social e de concentração residencial.

Uma crescente aceitação da homossexualidade na região mais liberal do país significa que os gays po- 
dem agora praticar um estilo de vida aberto sem medo de penalidades. Uma vez fora do armário, os gays podem ser atraídos para os guetos parcialmente desenvolvidos, para ficarem perto de outros semelhantes a eles e dos lugares da vida gay, aumentando o número de moradores gays nesses distritos (Levine, 1979, p. 201).

Os requisitos apontados pela definição original de gay ghetto não são cumpridos totalmente pela realidade investigada na ilha de Santa Catarina, mas alguns deles são contemplados. A exemplo do que evidencia a pesquisa desenvolvida por Perlongher (1988), a denominada concentração institucional limita-se, no contexto aqui investigado, à concentração e interesse de locais de lazer e espaços de paquera. Outros dois requisitos, de área de cultura e isolamento social, também são contemplados parcialmente pela realidade catarinense, conforme exploraremos a seguir. No entanto, quanto ao requisito de concentração residencial, o território investigado não corresponde a tal critério, devido, sobretudo, ao fato de que os espaços reconhecidos como territórios GLS em Florianópolis não se tratam de bairros, ${ }^{4}$ mas sim, de estabelecimentos comerciais voltados para o lazer.

Considerando a revisão teórica sobre a definição conceitual da problemática a qual a pesquisa se propôs analisar, o critério de decisão do uso de gueto como categoria de análise fez-se imperativo devido a um dado do campo: gueto aparecia na fala das freqüentadoras desses espaços para denominá-los.

Os diversos espaços urbanos assim reconhecidos na capital catarinense vêm se constituindo como tal há mais de quinze anos. Nesses espaços circulam determinadas práticas e vivências homoeróticas de diferentes sujeitos, ou melhor, de pessoas que, segundo Costa (1992), têm possibilidade de sentir diversos tipos de atração erótica ou de se relacionar fisicamente de diferentes maneiras com outras pessoas do mesmo sexo biológico que o seu. Este enfoque desloca o foco da investigação para as práticas possíveis no campo da sexualidade e não mais, exclusivamente, para a identidade.

Os reparos que provocam a aplicação literal do conceito de gay ghetto de Levine (1979), com sua carga de homogeneização, têm a ver não somente com a operação de modelização que esse contrabando ideológico poderia eventualmente acarretar. Remete também às dissimilitudes reais entre as populações homossexuais norte americanas ou metropolitanas, de um lado, e as brasileiras ou até latinoamericanas em geral, do outro (Perlongher, 1988).

Conforme anunciado anteriormente, uma diferença importante do conceito formulado pela Escola de Chicago e o aqui proposto para designar a realidade investigada é a de que a concentração de homossexuais no gueto florianopolitano é reconhecida como deliberada, ao contrário dos espaços que receberam a denominação norte-americana onde, num primeiro momento, a concentração de pessoas deveu-se à forte repressão social à homossexualidade em certas cidades, o que as levou a buscar a ocupação destes espaços na região dos Estados Unidos com maior aceitação (Levine, 1979).

Essa suposta deliberação não significa, entretanto, que o gueto florianopolitano não contemple a lógica da desqualificação social da diferença. Ao contrário, ele carrega o paradoxo de ser simultaneamente espaço de proteção e de exclusão. Dentro dos limites da boate os freqüentadores têm a liberdade para agirem de acordo com seus interesses e desejos, estando protegidos de agressões e manifestações de preconceito. Essa liberdade, contudo, se restringe a esse espaço. Portanto, a escolha desses sujeitos em freqüentar ambientes de lazer com seu parceiro(a) de forma segura e isenta de manifestações homofóbicas fica limitada aos locais reconhecidos e aceitos socialmente como guetos gays.

As concepções sobre o gueto aparecem vinculadas ao cerceamento do trânsito (e de alguns comportamentos) das informantes em outros espaços da cidade. Não que tais mulheres de fato não possam ir a outros ambientes. $\mathrm{O}$ cerceamento é mais sutile se aplica sob a forma da impossibilidade delas "ficarem à vontade com a namorada" nesses outros ambientes, como explicitou uma das informantes. Trata-se, portanto de um espaço de proteção e liberdade ao mesmo tempo em que transcende sua simples função de entretenimento e lazer.

O sentimento que estas mulheres estabelecem com o gueto, posteriormente à constatação de seu desejo afetivosexual, de sua atração por mulheres, é descrito como muito próximo daquela proteção, da liberdade e do conforto, associados ao espaço da casa. "A partir do momento que eu comecei, na minha adolescência, a freqüentar ambientes gays e ver que eu não era a única no mundo, que existiam várias pessoas como eu, eu passei a me sentir em casa!", afirma uma delas.

Em uma análise mais atenta para o uso das palavras que se lança mão para discutir ou explicar algum processo humano, a fala da informante remete a uma questão bastante discutida nos estudos de gênero: a hierarquia que abarca o sistema binário privado/público, casa/rua, ou numa adaptação apropriada para a problemática investigada, gueto/rua. Não como universos dicotômicos e excludentes, mas sim, como espaços de sociabilidade interpenetrantes e mutuamente constituídos.

Toda racionalidade que estruture e explique processos humanos a partir de uma lógica binária, de alguma forma estabelece certa dicotomia hierárquica entre os domínios do espaço privado e do espaço público, incorrendo ao erro de se apontar que o que é próprio de um domínio está inevitavelmente suprimido no outro. Dependendo da ótica, 
e no que diz respeito à racionalidade ocidental, a esfera pública encontra-se em uma posição de maior valor ou importância ao mundo privado, na medida em que é nessa instância social que ocorrem as tomadas de decisão, o exercício da cidadania e a legitimação dos direitos e deveres de cada pessoa para com a sociedade.

No que se refere ao gueto GLS enquanto espaço social de construção de subjetividades pode-se perguntar: como legitimar o exercício da cidadania, em situações cotidianas, por exemplo, o direito de ir e vir de um espaço a outro para sujeitos que estão mais vulneráveis no âmbito civil, devido à falta de respaldo jurídico em diversas situações que dizem respeito ao reconhecimento de suas parcerias, ao seu trânsito e, conseqüentemente, sua proteção e visibilidade? Como esperar que atravessem a soleira da porta da "casa" livremente e transitem na esfera pública com segurança e garantias de que serão respeitados quando, em contrapartida, paira no imaginário social uma norma que restringe sua liberdade a determinados espaços legitimados socialmente como próprios para alguns tipos de pessoas?

Tais dimensões atribuem-lhes um lugar social diferente dos demais, reconhecido e valorizado a partir de uma hierarquização da diferença, um mecanismo que transforma o diferente no desigual/inferior, como afirma Pierucci (1999):

ao se pôr a diferença, no ato mesmo de notá-la ou reconhece-la, ei-la desde logo valorizada ou desvalorizada, apreciada ou depreciada, prezada ou desprezada. (...) A diferença socialmente partilhada recebe sempre - já um sinal positivo (a nossa diferença, viva a diferença!) ou negativo (as diferenças dos outros, do outro) (p. 106).

Essa (des)valorização media o cerceamento do trânsito desse público específico a alguns territórios, dentre eles o gueto GLS. O trânsito livre restringe-se então a esse e não a outros lugares. A visibilidade é permitida ali e não para além de seus muros. Reproduzindo e legitimando a lógica de valorização da esfera do privado, da casa, do lar como espaço reservado às relações mais íntimas, aos segredos pessoais. É preciso, entretanto, orientar esta análise a partir da categoria gênero, que permite investigar sentidos atribuídos às relações sociais e às dimensões da vida dos sujeitos em nossa sociedade. Uma vez que esta tem sido uma categoria analítica importante para a compreensão das desigualdades de gênero. Neste sentido, não se pode sustentar a dicotomia das esferas privada e pública como dimensões auto-excludentes e hierarquicamente opostas. Mesmo que social ehistoricamente estejam imbricadas na lógica da hierarquização da diferença, essas dimensões envolvem relações de poder e se articulam mutuamente.

É no âmbito da experiência que se processam tanto o reconhecimento da vivência pessoal, particular e intrans- ferível das sensações e percepções corporalmente significadas, quanto à identificação social dos sujeitos com os outros que também vivenciam outras experiências neste mesmo território.

Os depoimentos das informantes são atravessados de significados compartilhados socialmente e que constituem os sentidos particulares de seus discursos e práticas. Tais significados podem ser entendidos como componentes do que Fuller (1997) descreve como o processo de recriação diária da identidade, através da atuação cotidiana dos sujeitos e do relato de si mesmo.

Os sujeitos que transitam por esse território são freqüentemente classificados e identificados como tendo suas experiências homoeróticas convertidas automaticamente em identidade homossexual. O sujeito é então reconhecido como a-histórico, naturalmente constituído e portador de uma essência homossexual que o faz ser o que é e comportar-se de determinada maneira, como se homens e mulheres fizessem parte exclusivamente de dois grupos humanos distintos, antagônicos e excludentes: heterossexuais ou homossexuais e, como se a sexualidade fosse absolutamente redutível às práticas sexuais.

Quanto ao tratamento do conceito de identidade, não se trata, tampouco, de adotar a noção de múltiplas identidades, a exemplo de Hall (1999), que afirma que as mudanças estruturais no mundo estão fragmentando e deslocando as identidades culturais de classe, sexualidade, etnia, raça e nacionalidade. Não compartilhamos aqui da concepção de identidades fragmentadas, ${ }^{5}$ como aparece nas discussões esse autor. Vale ressaltar, no entanto, que o debate pós-moderno tem confrontado de modo importante explicações que cristalizam as características identitárias, propondo a complexificação do conceito, o que possibilita pensar identidade enquanto unidade inacabada e fluída, constituída histórica e culturalmente a partir das posições que os sujeitos ocupam nas redes de sociabilidade (Fuller, 1997).

Quando indagadas sobre as motivações que as levavam a freqüentar territórios GLS, as entrevistadas relataram, cada uma a seu modo, a intenção de encontrarem pessoas com as mesmas preferências e vivências homoeróticas. Portanto é fundamental que a investigação não naturalize a experiência, ao contrário, como afirma Scott (1999), é necessário que se tratem todas as categorias de análise como contextuais, passíveis de contestação e contingentes.

Experiência não é uma palavra sem a qual podemos passar, apesar de ser tentador, dado seu uso corrente para essencializar a identidade e reificar o sujeito, abandoná-la totalmente. (...) Dada a ubiquiidade do termo, parece mais útil trabalhar com ele, analisar suas operações e redefinir seu significado. Isso exige um enfoque nos processos de produção da identidade, 
uma insistência na natureza discursiva da "experiência” e na política da sua construção (Scott, 1999, pp.47-48).

Pode-se perceber a importância da experiência de se sentir à vontade, protegida e ao mesmo tempo livre para se expressar diante dos outros. Entretanto, a análise evidencia que, no contexto territorial do gueto, o outro é um semelhante, alguém "igual a mim". Eis a cumplicidade, construída em processos de identificação. Como afirma Pinto (in Costa, 1992, p. 113) "O gueto não pode ser entendido simplesmente como marca de retraimento, medo de expor-se ou reafirmação da exclusão. É também, e, talvez principalmente, regido pelo princípio de prazer, de pertinência, da consciência de estar entre iguais".

O espaço da boate é reconhecido unanimemente pelas informantes como mediação importante para que os sujeitos posicionem-se diante do seu contexto social e histórico. Aparece como locus de (re)produção de modos de vida e conseqüentemente de constituição de subjetividades, tendo movimentos de aproximação, de afastamento, de identificação, de diferenciação. Esses processos são apontados pelas informantes que narram mudanças no contexto local, mas que também evidenciam os processos de transformações da contemporaneidade.

Não se trata apenas de um solo fértil para a criaçãoreprodução-perpetuação de dispositivos simbólicos de constituição dos sujeitos ou de modos de vida construídos a partir de interesses em comum. Parece muito mais do que isso. A boate é apontada pelas informantes como um reflexo da própria sociedade, do contexto sócio-urbanoeconômico da cidade.

As trocas sociais que se estabelecem no interior da boate constituem as relações mesmas desses sujeitos que encontram nesse espaço e nas outras pessoas que ali transitam a mediação para se posicionarem e agirem no contexto grupal.

Desse modo, as transformações se processam individualmente - do sujeito implicado no processo - e, simultaneamente, no coletivo - no âmbito das relações entre os sujeitos que transitam por esse espaço. Trata-se de um espaço de oportunidades, de estilos e gostos específicos, de modos de vida socialmente discriminados e pouco valorizados para além das paredes da boate, mas que, ali dentro, encontram condições adequadas para se legitimarem enquanto práticas historicamente constituídas e respaldadas coletivamente.

Quando indagadas sobre as razões que as fazem freqüentar esse espaço e não outro, as respostas das informantes apontam diversos motivos: cumplicidade, amizade, proteção, segurança e, fundamentalmente, liberdade. Tais elementos aparecem inexoravelmente ligados em um processo de identificação grupal pautado em vários elementos. Um deles em especial aparece como mola-mestra do pro- cesso de construção das relações sociais no gueto: a vivência mesma do homoerotismo por parte das mulheres que perambulam por esse espaço.

A possibilidade que algumas mulheres têm de sentir diversos tipos de atração erótica ou de se relacionar fisicamente de diversas maneiras com outras mulheres, aparece como o divisor de águas entre o espaço da boate - $\mathrm{e}$ numa análise mais generalizada, entre as áreas liberadas ${ }^{6}$ - e os demais espaços, restritos ao trânsito e às manifestações de desejo e espontaneidade desse público.

Todas as informantes, de uma forma ou de outra, encontram na orientação do desejo sexual, o motivo primário de suas incursões ao gueto, apesar de nem todas apontarem o "interesse de ficar com alguém" (no caso, uma mulher) como motivação fundamental para freqüentarem tais espaços. Ou seja, todas as informantes concordam com a premissa de que o que leva as mulheres à boate é a possibilidade de lá encontrarem outras mulheres iguais a elas, contudo, tal "encontro" não está relacionado necessariamente a um contato físico ou sexual.

O dado pertinente está na dinâmica do posicionamento dessas mulheres diante da escolha de transitar ou não por alguns lugares e nas concepções a respeito desses espaços em relação aos demais sujeitos que os freqüentam. Evidencia-se um paradoxo, uma ambigüidade que rege as relações sociais e os processos de constituição dos sujeitos que consiste, por um lado, na consciência de estar entre iguais, que corresponde a uma das nuances do processo de construção de subjetividades: a da identificação. Por outro lado, nesses territórios sui generis a segregação parece apresentar-se com uma nova roupagem, não mais a da intolerância explícita, violenta e sectária que originaram os ghettos, mas sim a de um outro tipo: um posicionamento de tolerância camuflado de aceitação. Condescendência por parte da sociedade para esses territórios em que públicos diferentes podem transitar com certa tranqüilidade. Neste sentido, a categoria áreas liberadas parece, de fato, bastante apropriada.

Se estas áreas são liberadas para o público GLS, é por que algumas outras the são restritas, espaços demarcados no próprio contexto urbano em que se insere, em que se transita. Restritas num sentido muito peculiar, restrição intimamente vinculada à questão da visibilidade.

A mútua construção simbólica de proteção/segregação lembra as discussões sobre região moral, ${ }^{7}$ que se refere ao contexto e à frequiência de certas populações em se agruparem, em áreas específicas do espaço urbano, suas perambulações (trânsito) à procura de sexo, diversão, prazeres e "outros vícios próximos à ilegalidade" (Perlongher, 1988). Tal definição abrange uma gama diversificada de espaços urbanos e, apesar do gueto poder estar implicado nesse contexto, a noção não o caracteriza em sua complexidade enquanto espaço onde se constituem redes de 
relações sociais, que implicam modos de vida, linguagem, sinalizações e trocas entre sujeitos com vivências homoeróticas.

A boate foi assimilada pela cidade de Florianópolis enquanto espaço de lazer voltado predominantemente ao público GLS e, neste sentido, as batidas policiais freqüentes nos locais da chamada região moral - descrita por Perlongher (1988) - não ocorrem ali, exatamente por não lhe ser atribuído um caráter de ilegalidade e clandestinidade.

Esse território diferencia-se por: 1) ter sido assimilado/ tolerado pela cidade enquanto espaço de lazer voltado predominantemente ao público GLS; 2) não preencher os critérios de classificação propostos pela Escola de Chicago, já que ele possui um caráter de "passagem", ou seja, de trânsito de pessoas que buscam diversão no mesmo espaço. Portanto, o critério concentração residencial ghetto não é cumprido, esta é uma característica fundamental desse território da capital catarinense: um local onde pessoas com afinidades e gostos semelhantes encontram-se para se divertir. "É inevitável que indivíduos que buscam as mesmas formas de diversão (...) devam de tempo em tempo se encontrar nos mesmos lugares. A população dessas áreas - que nem necessariamente reside, mas apenas perambula pelo local - tende a se segregar não apenas de acordo com seus interesses, mas de acordo com seus gostos e temperamentos" (Park, in Perlongher, 1988, p. 47).

Parece pertinente formular a discussão sobre tal constructo a partir da noção de territórios trabalhada por Perlongher (1988), que assinala exatamente a transitoriedade, a movimentação de pessoas nestas regiões. A noção de territorialidade possibilita pensar os movimentos dos códigos e as transações (trocas) simbólicas - que constituem e são constituídas pelas relações entre pessoas em um determinado espaço social - como engendrados em um plano de reconhecimento entre as pessoas, no qual significados são construídos a partir das experiências e legitimados (ou não) pelo grupo. Tal noção parece possibilitar o entendimento das concepções dos sujeitos que freqüentam o gueto como histórica e culturalmente construídas, no contexto das relações sociais.

Se Florianópolis não possui áreas residenciais e de comércio, predominantemente GLS (como acontece em algumas cidades norte-americanas) ao menos, promove um carnaval de rua que possui um caráter GLS bastante explícito e particular. ${ }^{8}$ Pode-se falar desse espaço urbano, nesses dias de fevereiro, como uma área liberada. Ou devese dizer, tolerada? A evidência da tolerância pode não significar uma mudança de comportamento dos habitantes por motivações humanitárias ou morais, como por exemplo, a constatação de que qualquer pessoa tem o direito de se divertir. Tal tolerância pode estar vinculada a outros aspectos, como o poder aquisitivo do público GLS. No entanto, apesar da evidência de que o público que freqüenta o gueto habitualmente é composto fundamentalmente por pessoas das camadas médias, não se pode ignorar o fato de que há gays e lésbicas em todas as camadas sociais. Ainda em relação ao carnaval, vale destacar que estudos clássicos da antropologia (DaMatta, 1980, 1981) destacamno como um período de inversão simbólica em relação às normas observadas em outros períodos do ano. Portanto, tal liberação (ou tolerância) característica do universo florianopolitano manifesta-se como uma expressão de transgressão que não se restringe ao universo pesquisado, mas se transpõem ao conjunto da sociedade.

A discussão da tolerância vinculada à problemática de classe remete a outras questões relacionadas às instituições sociais - como o não reconhecimento da união civil entre pessoas do mesmo sexo e a inexistência de uma legislação para adoção de crianças que leve em consideração os novos laços de família que constituem a sociedade brasileira. Remete também à cultura, no que se refere ao conjunto de regras, normas, valores contemplados pelo imaginário social que modelam nossas ações no cotidiano, práticas discursivamente constituídas. Essa estreita ligação entre fator econômico e tolerância, que parece envolver as trocas sociais entre o gueto e a cidade, também aparecem nos agenciamentos de subjetividade, nas relações sociais no interior do próprio gueto.

\section{Visibilidade e preconceito: \\ a dinâmica do espaço e do lugar}

A diferenciação entre espaço e lugar levantada por Giddens (1993), em sua discussão sobre o momento histórico contemporâneo, compreende o lugar como específico, concreto, familiar, peculiar e delimitado. $\mathrm{O}$ locus das práticas sociais, das relações específicas do cotidiano. Já o espaço, é compreendido como além dos limites do lugar, do específico concreto, transcendendo a noção de proximidade material. Esta diferenciação parece fundamental para compreendermos o processo de globalização da sociedade e de transformação da própria realidade investigada nessa pesquisa.

Nas sociedades pré-modernas, o espaço e o lugar
eram amplamente coincidentes, uma vez que as dimen-
sões espaciais da vida social eram, para a maioria
da população, dominadas pela presença - por uma
atividade localizada. (...) Nas condições da moder-
nidade..., os locais são inteiramente penetrados e
moldados por influências sociais bastante distantes
deles. O que estrutura o local não é simplesmente
aquilo que está presente na cena; a "forma visível"
do local oculta as relações distanciadas que deter-
minam sua natureza (Giddens, 1990, p.18).

Há uma complexidade inerente às relações sociais estabelecidas pelas mulheres no interior do gueto que molda o imaginário social daquele grupo e compõem o cenário do local enquanto território, dando formas e significados 
às posições dos sujeitos nesse trânsito. De fato, nas idas a campo pôde-se evidenciar alguns elementos apontados pelas informantes no que se refere a essas influências, que transcendem os limites do específico concreto, apesar de estarem materialmente representadas nos estilos de roupas, nos acessórios, nos gestos, nas linguagens, nas gírias e expressões usualmente utilizadas por elas. Trata-se de uma pluralidade de elementos e características constitutivas desse universo e de seus sujeitos.

As relações sociais estabelecidas entre as mulheres (com outras mulheres e homens) que transitam pelo gueto, constituem e significam esse território e são por ele constituídas. Como espaço de construção de subjetividades, o gueto media a própria construção dessas mulheres não apenas como pessoas com possibilidades de se relacionarem afetiva e sexualmente com outras do mesmo sexo que o seu, mas, sobretudo, como sujeitos no mundo.

O trânsito desses sujeitos no interior desses territórios indica o cerceamento das condutas dessas mesmas pessoas fora de seus limites. Reconhecido como lugar de proteção e legitimação de comportamentos e posturas, o gueto problematiza a dinâmica relacional dos domínios privado/ público, (re)produzindo modos de vida bastante peculiares e problematizando uma questão central, a da visibilidade.

A visibilidade consiste, nesse processo geográfico/ político, em uma estratégia de posicionamento público que remete a uma nitidez dos modos de vida constituintes desse universo.

A proteção surge exatamente da coesão que abarca essas coletividades. As chamadas áreas liberadas são espaços de legitimação da própria visibilidade. O propósito seria de garantir a liberdade de expressão e de condutas nesses espaços, construindo novas concepções entre os cidadãos e desconstruindo velhos paradigmas preconceituosos e equivocados a respeito de uma suposta "cultura gay" e das pessoas que dela fazem parte.

Para poderem se expressar, os gays sempre se juntaram - nos tempos modernos em bares e lugares social e culturalmente marcados. Quando se conscientizaram e sentiram-se suficientemente fortes para "assumirem" coletivamente, passaram a escolher lugares onde se sentiam seguros e podiam inventar novas vidas para si próprios. Os limites territoriais dos lugares selecionados tornaram-se as bases para o estabelecimento de instituições autônomas e a criação de uma autonomia cultural (Castells, 1999, p.249).

A idéia de que essa concentração apontada por Castells represente de fato uma autonomia cultural, mesmo no contexto norte americano, mereceria um debate mais profundo ao qual não nos propomos neste trabalho. Não se pode ignorar que tais bairros e seus respectivos estabelecimentos de comércio e moradia estão inseridos em um contexto urbano amplo e repleto de elementos que con- dicionam e influenciam os processos humanos nesses espaços específicos.

A mesma visibilidade acima problematizada, apresenta-se como um novo problema, quando evidenciamos que as condutas inseridas em uma suposta "cultura gay" perderiam seu objetivo fundamental, que é o de expor no contexto público uma orientação que é pessoal e, por isso mesmo, política. Mas o problema está justamente no contex to em que tal exposição se dá, de que vale expor condutas homoeróticas em espaços reconhecidamente homoeróticos? Eis a questão. Considerando-se como princípio da visibilidade o fato de que o que é percebido freqüentemente pelos sujeitos tende a tornar-se comum aos olhos de quem percebe, podemos discutir que as condutas homoeróticas como, por exemplo, andar de mãos dadas, beijar e abraçar, demonstrações de carinho e afeto em público entre pessoas do mesmo sexo, já são bastante comuns nas áreas liberadas.

Na esfera urbana da praça, da rua, das praias da cidade de Florianópolis, a conduta homoerótica é reconhecida como incomum, e esse estranhamento por parte de algumas pessoas às manifestações de carinho e afeto entre parceiros do mesmo sexo, é nutrido, dentre outras coisas, pela falta de visibilidade que esses sujeitos têm no espaço público. ${ }^{9}$ Ao ficar restrita ao contexto do gueto, ou às chamadas áreas liberadas, a conduta homoerótica acaba por ter pouca visibilidade. As relações sociais que se estabelecem no interior desse território contemplam problemáticas constitutivas das relações de gênero: igualdade/diferença, (in)visibilidade, proteção, exclusão, tolerância e preconceito. Problematizadas aqui não a partir de uma perspectiva binária de pensamento que analisa tais elementos como opostos excludentes, mas fundamentalmente, enquanto cambiantes em um processo, dinâmicas por excelência. Essas relações se processam no paradoxo que contempla o universo investigado: o da liberdade restrita a determinados espaços.

Se a tolerância para com o gueto e seus freqüentadores aparece sob a máscara da aceitação e se está diretamente ligada a outras questões que transcendem os limites desse território (que parece de fato se constituir como reflexo da própria sociedade), é porque existe uma ligação bastante forte entre o que se processa dentro desse espaço e o que o se passa fora de seus domínios. Cria-se então uma espécie de pacto silencioso que envolve os sujeitos e perpetua suas condutas dentro e fora do gueto.

O silêncio aqui se estende para tudo o que ocorre no interior desse território, mas aparece novamente como um silêncio relativo, pois na medida em que se estabelecem as condições necessárias, o "não dito" passa a ser entendido. Ou seja, o silêncio inscreve-se no contexto do homoerotismo e constitui esse universo. 
A análise dos sentidos que mulheres lésbicas atribuem às suas relações sociais no gueto GLS florianopolitano investigado, parece antecipar uma continuidade. Evidenciase uma perspectiva de manutenção desses espaços sob uma configuração ainda mais sectária no que se refere à separação dos públicos, muito mais do que uma possível agregação de diferentes públicos em locais compartilhados livremente. Pode-se evidenciar de um lado, a aceitação do homoerotismo restrito aos guetos e a segregação cada vez mais explícita desses territórios por parte daqueles que não o freqüentam; e, de outro lado, um preconceito às avessas que insiste em confirmar-se como baluarte de uma liberdade restrita, vigiada e permitida apenas em determinados espaços.

Cabe destacar, a critério de conclusão, que apesar do presente artigo enfatizar a dinâmica da territorialidade homoerótica a partir da perspectiva das mulheres e das relações por elas engendradas no contexto do gueto florianopolitano, existe, evidentemente, uma série de diferenças nos modos de ocupação e de construção de sentido por parte dos sujeitos que constituem e transitam por esse território. Sejam lésbicas, homens gays, bissexuais, travestis e transsexuais, entre outros. Neste sentido, vale ressaltar uma premissa importante no campo dos estudos de gênero, problematizada por Joan Scott: a necessidade em se atentar para as diferenças no interior da diferença, o que coloca em xeque o uso de categorias universais. Uma estratégia possível e necessária de enfrentar este "dilema da diferença" é desconstruir a lógica dicotômica hierárquica que subsidia o debate entre igualdade e diferença, na medida em que "a própria antítese esconde a interdependência dos dois termos, já que a igualdade não é a eliminação da diferença, e a diferença não exclui a igualdade" (Scott, 2000, p. 209). Assim, apesar deste artigo não assinalar as diferenças e particularidades pertinentes aos diversos públicos do gueto GLS florianopolitano (não apenas no que se refere ao gênero, mas também aos demais vetores que os constituem, classe, etnia, geração, etc.) destaca-se a importância em se saber que tais diferenças existem e que são constitutivas do contexto investigado. Portanto, a discussão que se apresentou teve como pano de fundo um pressuposto que se preocupa em trazer à luz uma armadilha conceitual, da qual as pesquisas de gênero tentam escapar com frequiência: a de se tomar igualdade e diferença como antíteses. Isso acaba por colocar o/a pesquisador/a em uma situação desconfortável e infecunda teoricamente: ter de escolher entre destacar a diferença, negando a igualdade ou, opostamente, enfatizar a igualdade em detrimento da diferença, perpetuando a lógica binária hierárquica tão ferozmente criticada no campo feminista.

Quando igualdade e diferença se discutem dicotomicamente, estruturam uma eleição impossível. Se alguém optar pela igualdade, estará forçado a aceitar que a noção de diferença é sua antítese. Se al- guém optar pela diferença, admitirá que a igualdade é inalcançável. (...) Nós, as feministas, não podemos renunciar à 'diferença'; tem sido nossa ferramenta analítica mais criativa. Não podemos renunciar à igualdade, ao menos quando desejemos nos referir aos princípios e valores de nosso sistema político" (Scott, 1999, p. 217).

Não se pode ignorar a importância política da tomada e fixação desses territórios pelas lésbicas, pelos gays, simpatizantes (e transgêneros), não apenas em Florianópolis, mas nas demais cidades brasileiras, ao longo da história. Nem tampouco, esquecer a mediação importante dos guetos, em um contexto histórico delimitado,${ }^{10}$ para a construção da visibilidade de sujeitos e modos de vida que questionam a heterossexualidade hegemônica. Apesar disso, o atual contexto parece demonstrar que é imprescindível a criação de novas estratégias de construção da equiidade e da visibilidade de gênero, para além dos limites dos guetos e de suas possíveis armadilhas como espaço de proteção e de exclusão.

\section{Notas}

Sigla referente a gays, lésbicas e simpatizantes.

2 Os termos entre aspas ao longo do texto correspondem às categorias nativas das informantes.

3 No ano de 2001, período em que foi desenvolvida a pesquisa, essa não era a única boate gay de Florianópolis, nem o único espaço que agregava um público predominantemente homossexual, apesar de ser a mais conhecida. Atualmente, no ano de 2005 a boate aqui pesquisada não funciona mais e existem pelo menos seis estabelecimentos (entre boates e bares) que são reconhecidos como espaços GLS. A fim de garantir o sigilo dos nomes dos frequientadores, facilitando o desenvolvimento da pesquisa e prevenindo problemas de ordem ética, iremos doravante referirmo-nos ao universo pesquisado simplesmente como a boate.

4 Sobre este recorte é interessante destacar a dissertação de mestrado defendida por Luiz Fernando Neves Cordova, "Amor sem vergonha - trajetórias pessoais e vida conjugal entre gays e lésbicas na comunidade do Ratones - ilha de santa Catarina". (um estudo de caso). Florianópolis, 2000.

5 O debate pós-moderno tem lançado mão da categoria “identidades fragmentadas" que parece aproximar o conceito da noção de papéis sociais. Para maiores esclarecimentos sobre essa problemática conceitual conferir Lago (1999).

6 Cf. Castells (1999). Categoria utilizada freqüentemente pelos grupos ativistas dos Estados Unidos substituindo o termo gueto. Perlongher (1988), sobre o conceito de Robert Park.

8 O carnaval gay de Florianópolis é também conhecido como "carnaval do Roma", recebeu esse nome pelo fato dos foliões se concentrarem, principalmente, em frente a um bar assim chamado, que se situava há muitos anos atrás na Avenida Hercílio Luz no centro da cidade. Atualmente o bar não existe mais, porém, continua dando nome à festa.

9 Exceto em eventos como a Parada do Orgulho Gay, que acontece uma vez por ano em São Paulo, mas cujas manifestações de afeto em público também podem ser analisadas sob uma ótica de tolerância restrita e, portanto, legitimada apenas nessa data comemorativa. 
10 No que se refere ao Brasil, mais precisamente no período da abertura, como se pôde analisar na obra de Macrae (1990).

\section{Referências}

Bardin, L. (1977). Análise de Conteúdo. Lisboa: Edições 70.

Bott, E. (1976). Família e rede social. Rio de Janeiro: Francisco Alves.

Castells, M. (1984). The city and the grassroot. Berkeley: University of California Press.

Castells, M. (1999). O poder da identidade. São Paulo: Paze Terra.

Costa, J. F. (1992). A inocência e o vício: estudos sobre o homoerotismo. Rio de Janeiro: Relume-Dumará.

Costa, J. F. (1996). O referente da identidade homossexual. R. Parker, R. M. Barbosa (Eds.), Sexualidades brasileiras (pp. 63-89). Rio de Janeiro: Relume/Dumará.

Damatta, R. (1980). Carnavais, malandros e heróis: para uma sociologia do dilema brasileiro. Rio de Janeiro: Jorge Zahar.

Damatta, R. (1981). Universo do carnaval: imagens e reflexões. Rio de Janeiro: Pinakhotteke.

Fry, P. (1982). Da hierarquia à igualdade: a construção histórica da homossexualidade no Brasil. In p. Fry (Ed.), Para inglês ver (pp. 87-115). Rio de Janeiro: Zahar.

Fry, P., \& Macrae, E. (1983). O que éhomossexualidade? São Paulo: Brasiliense.

Fuller, N. (1997). Identidades masculinas. Lima: Fondo Editorial de la Pontificia Universidad Católica del Perú.

Giddens, A. (1993). A transformação da intimidade: sexualidade, amor e erotismo nas sociedades modernas. São Paulo: UNESP.

Hall, S. (1999). A identidade cultural na pós-modernidade. Rio de Janeiro: DP\&A.

Lago, M. C. S. (1999). Identidade: a fragmentação de um conceito. In A. L. Silva, M. Lago, \& T. Ramos, A. L. (Eds.), Falas de Gênero (pp. 119-129). Florianópolis: Mulheres.

Levine, M. P. (1979). Gay Ghetto. Journal of Homosexuality, 4 (Summer). (Reprinter in expanded form as "YMCA: the social organization of gay male life". In: Gay macho: the life and death of homosexual clone. New York: New York University Press, 1979. pp. 30-54).

Macrae, E. (1990). A construção da igualdade: movimento, comunidade e identidade. In. E. Macrae (Ed.), A construção da igualdade: identidade sexual e política no Brasil da abertura (pp. 279-305). Campinas: UNICAMP.

Martin, B. (1992). Sexual Practice and Changing Lesbian identities. In M. Barrett, \& A. Phillips (Eds.), Destabilizing Theory: contemporary Feminist Debates. Cambridge: Polity Press.

Parker, R., \& Barbosa, R. M. (1996) (Ed.), Sexualidades brasileiras. Rio de Janeiro: Relume Dumará.

Perlongher, N. (1993). Territórios Marginais. In A. Barenblitt (Ed.), Saúde Loucura: Grupos e Coletivos (Vol. IV, pp. 46-69). São Paulo: HUCITEC.

Perlongher, N. (1988). O Negócio do Michê: a prostituição viril. São Paulo: Brasiliense.
Perucchi, J. (2001). Investigando os sentidos que mulheres lésbicas atribuem às relações sociais que estabelecem em um gueto GLS de Florianópolis. Dissertação de Mestrado não-publicada, Programa de Pós-graduação em Psicologia, Universidade Federal de Santa Catarina. Florianópolis, SC.

Pierucci, A. F. (1999). Ciladas da Diferença. São Paulo: Curso de Pós-graduação em Sociologia da Universidade de São Paulo/ Ed. 34.

Pinto, C. R. J. P. (1992). Movimentos Sociais: Espaços Privilegiados da Mulher Enquanto sujeito Político. In A. O. Costa, \& C. Bruschini (Ed.), Uma Questão de Gênero (pp. 127-150). Rio de Janeiro, Rosa dos Tempos/ São Paulo, Fundação Carlos Chagas.

Pollak, M. (1985). A homossexualidade masculina, ou: a felicidade no gueto? In P. Ariès, \& A. Bèjin (Eds.), Sexualidades Ocidentais. (pp. 54-76). São Paulo: Brasiliense.

Portinari, D. B. (1989). O Discurso da homossexualidade feminina. São Paulo: Brasiliense.

Scott, J. (1990). Gênero, uma categoria útil de análise histórica. Educação e Sociedade, 16(2), 5-22.

Scott, J. (1999). Experiência. In A. L. Silva, M. Lago, \& T. Ramos (Eds.), Falas de Gênero (pp. 21-55). Florianópolis: Mulheres.

Scott, J. (2000). Igualdade versus diferença: os usos da teoria pósestruturalista. Debate Feminista (Cidadania e Feminismo), $n^{o}$ especial, 203-222.

Spencer, C. (1996). Homossexualidade: uma história. Rio de Janeiro: Record.

Swain, T. N. (1999). Feminismo e lesbianismo: a identidade em questão. In K. A. M. Bessa (Ed.), Cadernos Pagu (pp. 109-120). Campinas, SP: UNICAMP.

Wirth, L. (1969). The Ghetto. In L. Wirth (Ed.), On cities and social life (Selected Papers, pp. 84-98). Chicago: University of Chicago Press.

Maria Juracy Filgueiras Toneli é Professora Doutora do Departamento de Psicologia da Universidade Federal de Santa Catarina.

juracy@cfh.ufsc.br

Juliana Perucchi é Doutoranda do Programa de Pós-graduação em Psicologia da Universidade Federal de Santa Catarina. jperucchi@hotmail.com

\section{Territorialidade homoerótica: apontamentos para os estudos de gênero}

Maria Juracy Filgueiras Toneli e Juliana Perucchi

Recebido: $12 / 08 / 2005$

$1^{\text {a }}$ revisão: $25 / 01 / 2006$

$2^{\mathrm{a}}$ revisão: $29 / 05 / 2006$

Aceite final: 06/06/2006 